\title{
The impact of intrinsic anhydrite in an experimental calcium sulfoaluminate cement from a novel, carbon-minimized production process
}

\author{
Gabriel Jen • Solon Skalamprinos • Mark Whittaker • \\ Isabel Galan · Mohammed S. Imbabi · Fredrik P. Glasser
}

Received: 3 August 2016/Accepted: 14 February 2017

(C) The Author(s) 2017. This article is published with open access at Springerlink.com

\begin{abstract}
Calcium sulfoaluminate clinker produced through a previously described novel production process, generating further economies of carbon emission minimization and sulfur use efficiency, is tested for performance as a cementitious binder. The reactivity levels of major phases, including ye'elimite, two polymorphs of belite and anhydrite are found to produce a viable product characterized by rapid hydration. Through investigation, the reactivity is linked to the unique distribution of crystalline phases present within cement grains. It is inferred that both microstructure and mineralogy are responsible for the undesirable set behaviour encountered. The causality of this problem is further investigated and determined to be a consequence of the intrinsic anhydrite component for which remediation solutions are described. The resultant mortar compression strengths are determined for the subject cement in order to characterize its potential in relation to ordinary Portland cement.
\end{abstract}

Keywords Calcium sulfoaluminate $\cdot$ Anhydrite . Flash set $\cdot$ False set

G. Jen · M. Whittaker · M. S. Imbabi ( $\varangle)$

School of Engineering, University of Aberdeen, Aberdeen AB24 3UE, UK

e-mail: m.s.imbabi@abdn.ac.uk

S. Skalamprinos · I. Galan · F. P. Glasser Department of Chemistry, University of Aberdeen, Aberdeen AB24 3UE, UK

\section{Introduction}

Production of ordinary Portland cement (PC) is acknowledged to significantly contribute to global greenhouse gas emissions [1-3] and has been identified as an area in need of research and development of new processes and materials $[4,5]$. Predominantly, the $\mathrm{CO}_{2}$ emissions of $\mathrm{PC}$ are attributed, in near equal measure, to the calcination of limestone, providing the calcium oxide component of clinker, and hydrocarbon fuel combustion to achieve the necessary kiln temperature (nominally $1450{ }^{\circ} \mathrm{C}$ ). Researchers have investigated calcium sulfoaluminate (CSA) based cements as a potential commercial alternative to PC, recognizing the opportunity to lower $\mathrm{CO}_{2}$ emissions during production [6-9]. A lower carbon footprint is achieved due to the calcium deficiency of CSA with respect to $\mathrm{PC}$ reducing the quantity of limestone required, as well as requiring a lower kiln operating temperature, $1250{ }^{\circ} \mathrm{C}$ versus $1450{ }^{\circ} \mathrm{C}$, for the conversion of raw feed materials into the intended cementitious phase ye'elimite $\left(\mathrm{C}_{4} \mathrm{~A}_{3} \overline{\mathrm{S}}\right)$ [7, 10-13]. An attempt to maximize further reduction of the carbon footprint attributable to CSA cement, through partial substitution of conventional hydrocarbons by sulfur rich fuels, has been investigated by Hanein et al. [14]. This novel method finds further process efficiency through the sequestration of $\mathrm{SO}_{2}$ from the combustion atmosphere into sulfate-bearing clinker phases. Computational thermodynamics and laboratory experiments 
have indicated that the primary impact upon the clinker chemistry of the novel production process generated in a controlled $\mathrm{SO}_{2} / \mathrm{O}_{2}$ atmosphere is a stabilizing influence upon the desired phases within the kiln's operational range [15-17].

Within the anticipated range of CSA cement-appropriate kiln temperatures, computational thermodynamics predicts complex stability oscillating between mixtures richer in calcium sulfate/gehlenite $(\mathrm{CS} /$ $\left.\mathrm{C}_{2} \mathrm{AS}\right)$ and belite/ye'elimite $\left(\mathrm{C}_{2} \mathrm{~S} / \mathrm{C}_{4} \mathrm{~A}_{3} \overline{\mathrm{S}}\right)$ dependent upon raw mix composition as well as both temperature and $\mathrm{SO}_{2}$ and $\mathrm{O}_{2}$ partial pressures. An unanticipated content of calcium sulfate, in the form of anhydrite, may persist in the clinker output given thermodynamic or kinetic limitations of the system. Such occurrences can arise given: (a) a shortage of alumina/excess of lime in the input feed, (b) inadequate temperature to convert calcium sulfate/gehlenite to belite/ye'elimite, (c) incomplete conversion occurring due to insufficient residence time, or (d) non-optimum $\mathrm{SO}_{2}$ and $\mathrm{O}_{2}$ partial pressure in the kiln atmosphere.

As the kinetics and mechanisms of thickening and sustained workability in CSA cements are less well documented than the literature base of PC, the CSA investigation and discussion described here is made on the basis of phenomena familiar to PC practice. Hardburned and potentially poorly reactive calcium sulfate within CSA clinker output is differentiated from typically more reactive, additive calcium sulfate sources introduced during the grinding/blending process. Workability problems encountered in PC cements having an improper calcium sulfate component, nominally anhydrite/hemihydrate $\left(\mathrm{C} \overline{\mathrm{S}} / \mathrm{C} \overline{\mathrm{S}} \mathrm{H}_{0.5}\right)$, are attributed to the hydration of an open gypsum $\left(\mathrm{CS}_{\bar{S}} \mathrm{H}_{2}\right)$ network generating "false set" behaviour [18]. False setting cements are known to exhibit significant thickening during the early stages of hydration that is overcome with additional mixing energy input before regaining a normal consistency [19]. Such behaviour is strongly differentiated from "flash set" cements that undergo near immediate permanent stiffening [20]. PC having a deficiency of blended gypsum can experience flash set owing to the rapid hydration of tricalcium aluminate $\left(\mathrm{C}_{3} \mathrm{~A}\right)$, forming calcium aluminate hydrates accompanied by a large evolution of heat, from which normal consistency cannot be recovered despite additional mixing [21-23]. Both false and flash set behaviour are typically tested for and avoided in commercial cements. Consequently, for standard applications in which CSA cements may be deployed in direct replacement of PC using conventional mixing and placing technology and techniques, cement composition and its influence upon setting time behaviour must be validated.

The resulting yield of the primary CSA clinker batch produced using sulfur fuels [17] is investigated for hydration characteristics, being a necessary step in verifying the potential of the experimental processing technique output. For comparison, a preliminary batch of clinker produced from similar raw material feed and kiln operating conditions and a reference commercial CSA cement are presented to effectively highlight the chemical and morphological characteristics responsible for the performance of the primary experimental clinker batch. The attainment of mechanical strength is judged, as one criteria of performance, relative to standardized demands.

\section{Methods}

\subsection{Observations of the as-received clinkers}

Observations of the anhydrous clinker phase distribution were made using a Carl Zeiss EVO MA10 scanning electron microscopy (SEM). Epoxy impregnated samples of anhydrous cement were prepared and subsequently polished to a fineness of $0.25 \mu \mathrm{m}$ for observation in the backscattered electron (BSE) mode, with the SEM operating at $20 \mathrm{keV}$. Prior to analysis, the samples were carbon coated to prevent sample charging. Spot analyses and elemental mapping were collected using an Oxford Instruments $80 \mathrm{~mm}^{2}$ energy dispersive X-ray (EDX) spectrometer.

Oxide composition of the clinkers was measured by $\mathrm{X}$-ray fluorescence (XRF) on compacted powder samples in an energy dispersive Rigaku NEX $\mathrm{QC}^{+}$ benchtop instrument. A certified sulfoaluminate clinker reference material, Fluxana NCS DC62123, was used to calibrate a set of internal standards from which measurements were quantified.

Phase composition was measured by X-ray diffraction (XRD) using a Phillips Empyrean diffractometer in the Bragg-Brentano geometry with a $\mathrm{Cu} \mathrm{K}-\alpha \mathrm{X}$-ray source, a Ge monochromator and a PIXcel1D detector operating at $45 \mathrm{kV}$ and $40 \mathrm{~mA}$. Back loaded samples 
were measured from $5^{\circ}$ to $70^{\circ} 2$-theta in steps of $0.0132^{\circ}$ while being continuously rotated at 15 revolutions per minute. Phase quantification by way of Rietveld refinement was calculated using GSAS software [24], with fitting determined by the PseudoVoigt peak shape function [25] and asymmetry correction [26]. The scale factor of all phases, lattice parameters, background, zero shift and Pseudo Voigt function variables (Gaussian $\mathrm{W}$ term and Lorentzian isotropic strain broadening) were refined.

\subsection{Early age hydration: dissolution and precipitation}

Electrical conductivity measurements of cement dissolution were conducted on solutions having a 1:100 ratio of solids to distilled water at $22{ }^{\circ} \mathrm{C}$. Conductivity as a function of dissolution time was monitored using a Thermo Scientific Orion 3 Star conductivity meter.

Setting time was measured on pastes with a water to cement $(\mathrm{w} / \mathrm{c})$ ratio of 0.485 following the procedure of EN 196-3 modified to test cement pastes using a Vicat apparatus. For this modification, cement paste samples were cast into $25 \mathrm{~mm}$ diameter $\times 50 \mathrm{~mm}$ tall plastic cylinder molds and subjected to the same needle and drop height as designated for conventional mortar samples. A final set time was determined based upon judgement of the impression left by the penetration needle in the same manner as EN 196-3.

Measurements of heat evolution during the initial stages of cement hydration were made using a Calmetrix I-Cal 4000 calorimeter in a controlled $25{ }^{\circ} \mathrm{C}$ environment. Samples consisted of 5 grams of cement and 2.425 grams of distilled water (equal to a $0.485 \mathrm{w} / \mathrm{c}$ ratio). The constituents were brought to temperature prior to undergoing $20 \mathrm{~s}$ of hand mixing, ex situ of the calorimeter, with measurements subsequently recorded for up to 3 days. The chosen 0.485 w/c ratio provided sufficient water to fully hydrate the fast acting cement phases $\left(\mathrm{C}_{4} \mathrm{~A}_{3} \overline{\mathrm{S}}\right.$ and $\alpha^{\prime}-\mathrm{C}_{2} \mathrm{~S}$ where present) respective of the available sulfate content.

Qualitative observations of phase dissolution and hydrate precipitation were made by XRD on pastes prepared with an increased w/c ratio of 0.65 . This increase in water content relative to prior testing was dictated by a workability demand, taking into account the rapid stiffening characteristics experienced during the mixing process and the necessary consistency to allow for sample casting as described later. The pastes were dried by solvent exchange with acetone and subsequent drying at $30{ }^{\circ} \mathrm{C}$ for up to $24 \mathrm{~h}$ to limit drying damage incurred by the ettringite-rich matrix [27]. Measurements were taken after 30, 60, $120 \mathrm{~s}$ and in increments of $2 \mathrm{~min}$ thereafter, up to $10 \mathrm{~min}$ of hydration.

Thermogravimetric analysis (TGA) of specimens having the same drying procedure as those described above were measured by a Stanton Redcroft STA780 with a temperature ramp rate of $10{ }^{\circ} \mathrm{C} / \mathrm{min}$ over a range of $30-1000{ }^{\circ} \mathrm{C}$ in a nitrogen atmosphere. The data presented is truncated as all expected hydrates of the CSA system experience dehydration prior to $600{ }^{\circ} \mathrm{C}$; further, no carbonate hydrates were observed at temperatures up to $1000{ }^{\circ} \mathrm{C}$.

Fracture surfaces of pastes cured for $24 \mathrm{~h}$ were observed by SEM operating in the secondary electron mode to have a greater understanding of the impact of mixture constituents upon the morphology of hydration products.

\subsection{Later hydration: reactivity and strength gain}

Unconfined compressive strength was measured on mortar specimens, having a sand to cement ratio of 2.75. Mixes prepared with ASTM C778 sand in a Hobart mixer at a w/c ratio of 0.485 produced a mix too stiff for adequate compaction. This was overcome by either adding a set retarding mixture compromised of $0.5 \%$ reagent grade citric acid and 5\% reagent grade gypsum by weight of cement, or by increasing the w/c ratio to 0.65 . The resulting mortars were compacted via vibration into $50 \mathrm{~mm} \times 50 \mathrm{~mm} \times 50 \mathrm{~mm}$ cubes. Following continuous curing in water for 1, 3, 7 and 28 days, compression measurements were performed on a $500 \mathrm{kN}$ Instron 8500 test frame at a fixed displacement rate of $0.25 \mathrm{~mm} / \mathrm{min}$ and a data sampling frequency of two hertz.

Complimentary cement phase reactivity was measured by XRD with the same setup described previously on cement pastes having a w/c ratio of 0.485 . The degree of hydration was interpreted as the weight percent reduction of the clinker phases over time. Quantification was carried out using GSAS with the same fitting parameters as described above. The true amount of crystalline hydrates in the hydrated samples, and complimentary amorphous content, was determined using the G-factor method [28-31] with crystalline $\mathrm{Al}_{2} \mathrm{O}_{3}$ (NIST SRM676a) serving as a standard. The obtained data was normalised to $100 \mathrm{~g}$ of anhydrous cement. 


\section{Materials}

This study focused primarily on the primary yield of an experimental CSA clinker produced using the novel production method described previously by Hanein et al. [17]. For comparison, this investigation was complimented by assessment of one of the preliminary test batches of clinker. Both clinkers were made using the same raw feed (a mixture of limestone, bauxite and clay), however, fluctuations in the kiln performance with time led to the differing compositions observed.

Alongside the experimental clinkers, a commercial CSA cement produced in a conventionally fueled kiln was comparatively assessed (Shenzhen Chenggong Building Materials Co., Grade 72.5 rapid-setting CSA). For serving as a reference to the experimental clinker, the commercial CSA cement was blended with reagent grade anhydrite to achieve a similar content of calcium sulfate.

\section{Results}

\subsection{Observations of the as-recieved clinkers}

Results from the compositional analysis of the CSA cements investigated are provided in Table 1. Each of the cements incorporated in this investigation contained both cubic and orthorhombic polymorphs of
$\mathrm{C}_{4} \mathrm{~A}_{3} \overline{\mathrm{S}}$ and the $\beta$-polymorph of $\mathrm{C}_{2} \mathrm{~S}$, while the experimental CSA additionally contained the $\alpha^{\prime}$ polymorph of $\mathrm{C}_{2} \mathrm{~S}$. The minor phases identified by $\mathrm{XRD}$ in the experimental cement were comprised of ferrite $\left(\mathrm{C}_{4} \mathrm{AF}\right)$, calcium titanate $(\mathrm{CT})$ and free lime $(\mathrm{CaO})$. The minor phases of the preliminary batch consisted of $\mathrm{C}_{3} \mathrm{~A}$, ternesite $\left(\mathrm{C}_{5} \mathrm{~S}_{2} \overline{\mathrm{S}}\right)$ and $\mathrm{CT}$. In the commercial CSA, these minor phases included CT, merwinite $\left(\mathrm{C}_{3} \mathrm{MS}_{2}\right)$, mayenite $\left(\mathrm{C}_{12} \mathrm{~A}_{7}\right)$ and magnesia (MgO).

Compositional distribution of the experimental CSA as determined by SEM-EDX is shown in Fig. 1a with element mapping of $\mathrm{CaO}, \mathrm{Al}_{2} \mathrm{O}_{3}, \mathrm{SiO}_{2}$ and $\mathrm{SO}_{3}$ highlighted. For comparison, the preliminary batch is shown in Fig. 1b while the commercial CSA is shown in Fig. 1c. Strong differentiation is noted between the experimental clinkers $(1 \mathrm{a} / \mathrm{b})$ and the commercial product (1c) with respect to phase distribution. The greyscale corresponds to the mean atomic number, whereby white denotes $\mathrm{Fe} / \mathrm{Ti}$ rich regions $\left(\mathrm{C}_{4} \mathrm{AF} / \mathrm{CT}\right)$, light grey being $\mathrm{Ca} / \mathrm{Si}$ rich $\left(\mathrm{C}_{2} \mathrm{~S}\right)$, dark grey being $\mathrm{Al}$ rich $\left(\mathrm{C}_{4} \mathrm{~A}_{3} \overline{\mathrm{S}}\right)$ and black being the impregnating resin.

\subsection{Early age hydration: dissolution and precipitation}

Conductivity measurements of the experimental CSA cement having a Blaine fineness of $4000 \mathrm{~cm}^{2} / \mathrm{g}$

Table 1 Quantified CSA compositions

\begin{tabular}{|c|c|c|c|c|c|c|c|c|c|c|c|c|}
\hline & $\mathrm{C}_{4} \mathrm{~A}_{3} \overline{\mathrm{S}}^{\mathrm{c}}$ & $\mathrm{C}_{2} \mathrm{~S}^{\mathrm{c}}$ & $\mathrm{C} \overline{\mathrm{S}}^{\mathrm{d}}$ & $\mathrm{C}_{2} \mathrm{AS}^{\mathrm{d}}$ & $\mathrm{CT}^{\mathrm{d}}$ & $\mathrm{C}_{4} \mathrm{AF}^{\mathrm{d}}$ & $\mathrm{CaO}^{\mathrm{d}}$ & $\mathrm{C}_{3} \mathrm{~A}^{\mathrm{d}}$ & $\mathrm{C}_{5} \mathrm{~S}_{2} \overline{\mathrm{S}}^{\mathrm{d}}$ & $\mathrm{C}_{3} \mathrm{MS}_{2}^{\mathrm{d}}$ & $\mathrm{C}_{12} \mathrm{~A}_{7}^{\mathrm{d}}$ & $\mathrm{MgO}^{\mathrm{d}}$ \\
\hline \multicolumn{13}{|c|}{ Mineralogy [weight percent ${ }^{a}$ ] } \\
\hline Experimental CSA & $12 / 24$ & $15 / 28$ & 10 & 4 & 2 & 2 & 2 & - & - & - & - & - \\
\hline Preliminary Batch & $19 / 24$ & $-/ 35$ & 14 & - & 1 & - & - & 4 & 3 & - & - & - \\
\hline \multirow[t]{2}{*}{ Commercial $\mathrm{CSA}^{\mathrm{b}}$} & $4 / 44$ & $-/ 19$ & 10 & 11 & 5 & - & - & - & - & 3.5 & 3 & 0.5 \\
\hline & & $\mathrm{Al}_{2} \mathrm{O}_{3}$ & & $\mathrm{SiO}_{2}$ & & $\mathrm{SO}_{3}$ & & $\mathrm{CaO}$ & & $\mathrm{TiO}_{2}$ & & $\mathrm{Fe}_{2} \mathrm{O}_{3}$ \\
\hline \multicolumn{13}{|c|}{ Oxide content [weight percent] $^{e}$} \\
\hline \multirow{2}{*}{\multicolumn{2}{|c|}{$\begin{array}{l}\text { Experimental CSA } \\
\text { Commercial CSA }\end{array}$}} & \multicolumn{2}{|l|}{21.1} & \multicolumn{2}{|l|}{15.3} & \multicolumn{2}{|l|}{9.8} & \multicolumn{2}{|l|}{48.3} & \multicolumn{2}{|l|}{1.0} & 2.0 \\
\hline & & \multicolumn{2}{|l|}{27.8} & \multicolumn{2}{|l|}{10.5} & \multicolumn{2}{|l|}{12.0} & \multicolumn{2}{|l|}{45.5} & 1.4 & & 2.2 \\
\hline \multicolumn{13}{|c|}{ a The relative error of the XRD-quantified mineral contents is estimated to be on the order of $5 \%$} \\
\hline \multicolumn{13}{|c|}{ b The $\mathrm{C} \overline{\mathrm{S}}$ content of the commercial CSA listed is a product of blending with anhydrite post-clinkerization } \\
\hline \multicolumn{13}{|c|}{$\begin{array}{l}\text { The reported values reflect the content of cubic/orthorhombic polymorphs of } \mathrm{C}_{4} \mathrm{~A}_{3} \overline{\mathrm{S}}[41,42] \text { and the } \alpha^{\prime} / \beta \text { polymorphs of } \mathrm{C}_{2} \mathrm{~S} \\
{[43,44] \text { respectively }}\end{array}$} \\
\hline \multicolumn{13}{|c|}{ d XRD reference patterns sources [45-49] } \\
\hline \multicolumn{13}{|c|}{$\begin{array}{l}\text { Quantification of low content alkali and magnesium oxides were not achieved on the XRF equipment } \\
\text { absorption effects }\end{array}$} \\
\hline
\end{tabular}




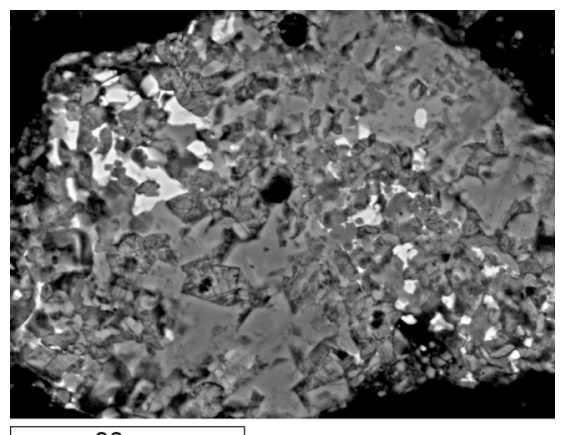

$30 \mu \mathrm{m}$

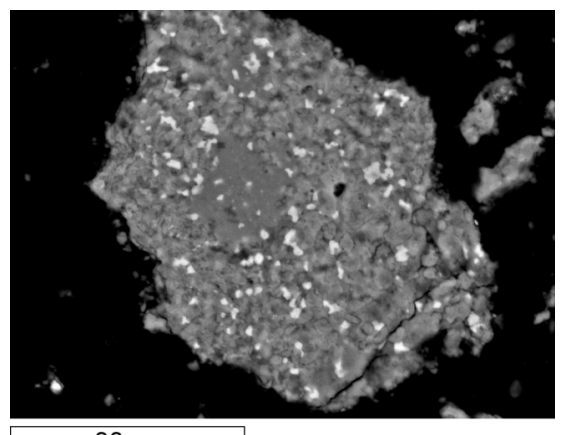

$30 \mu \mathrm{m}$

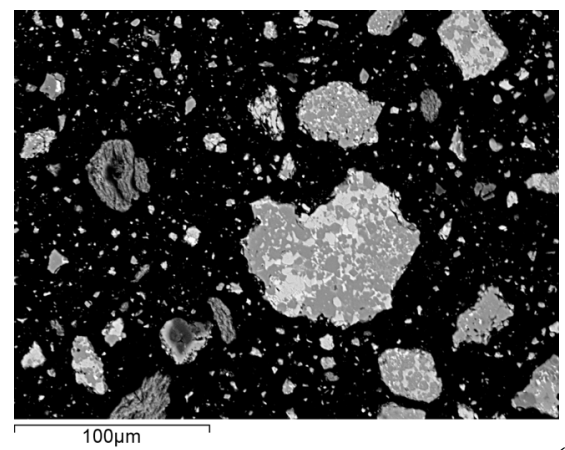

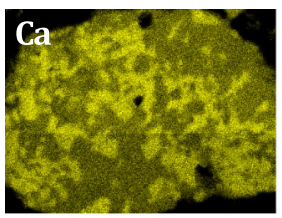
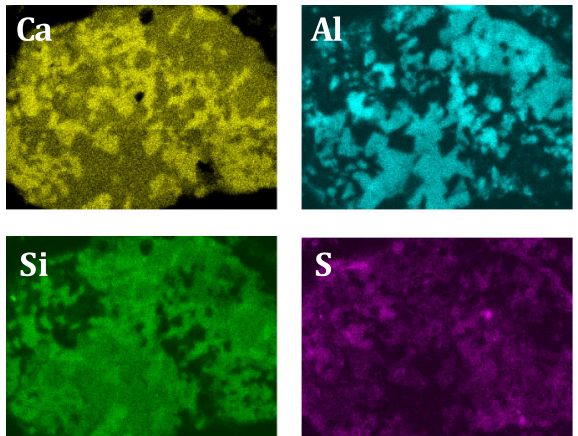

(a)
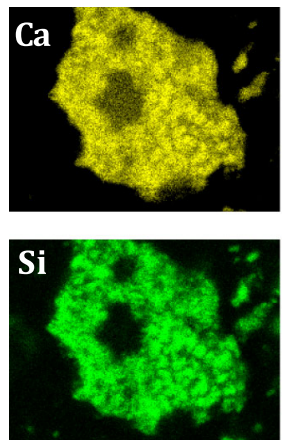

(b)
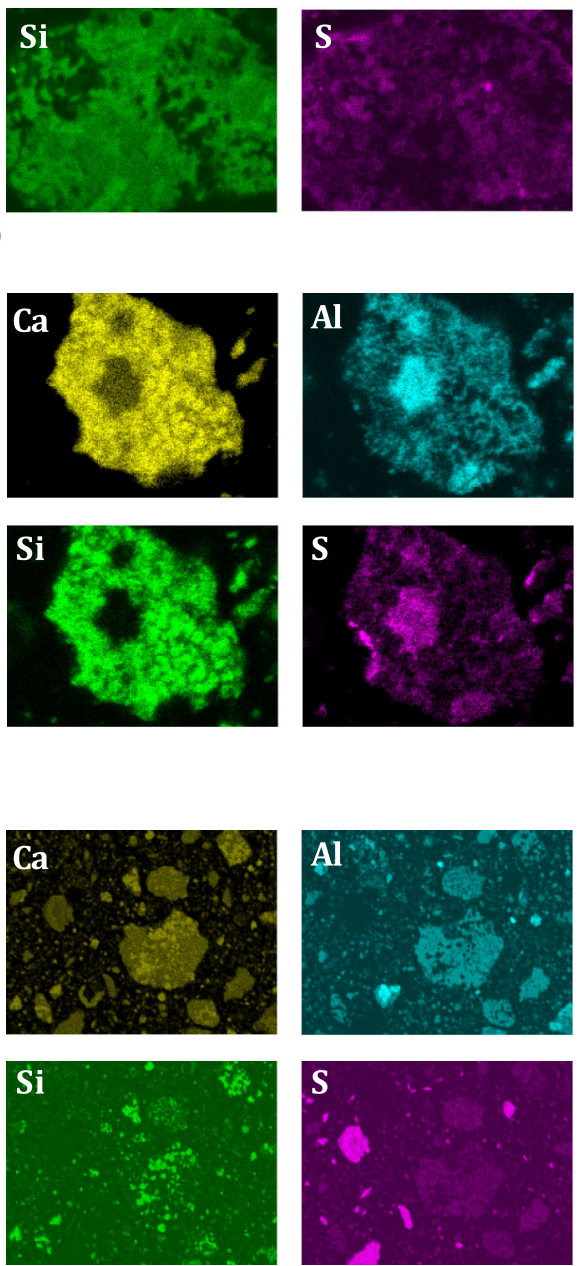

(c)

Fig. 1 Anhydrous, epoxy-impregnated SEM-EDX analysis of a experimental CSA cement, b preliminary CSA batch and c commercial CSA cement having $\bar{C} \bar{S}$ introduced by blending for contrast

confirmed the rapid nature of cement dissolution, supporting a markedly higher conductivity within $30 \mathrm{~s}$ of commencing hydration (Fig. 2). Empirically, the magnitude and rate of reaching such conductivity was on a par with that encountered when dissolving anhydrite of similar specific surface area in distilled water. In contrast, the development of a similar conductivity in solutions of the preliminary batch as well as the commercial CSA was a much slower process. Comparative performance of apparent setting time is shown in Table 2 for each mixture at a w/c ratio of 0.485 . Additional mixtures of the experimental CSA cement were prepared with additives known to have set-retarding properties to examine their impact, these included citric acid monohydrate at 0.5 weight percent cement with and without gypsum at five weight percent cement. As determined by Vicat, the setting time of the experimental CSA cement was not 


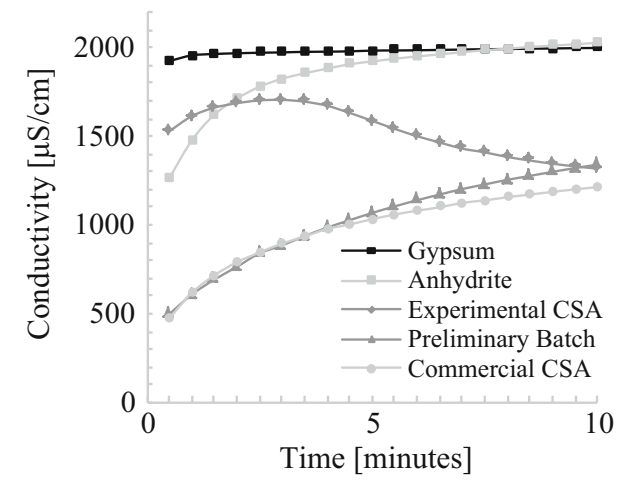

Fig. 2 Conductivity time history of CSA cements in distilled water at $22{ }^{\circ} \mathrm{C}$

significantly impacted by the addition of citric acid alone, but was markedly lengthened by the combined presence of citric acid and additional gypsum.

Qualification of early hydrate formation and speciation at discrete intervals over the first $10 \mathrm{~min}$ of hydration is shown in Fig. 3. Both the XRD and TGA patterns show that quantifiable changes within the first $30 \mathrm{~s}$ were negligible, but the rate of ettringite crystallization accelerated rapidly thereafter. This crystallization was concurrent with the consumption of ye'elimite and anhydrite. Early ettringite formation reached a plateau at 4 min after which continued formation and associated consumption of ye'elimite and anhydrite were stabilized.

Over the first $24 \mathrm{~h}$ of hydration, heat evolution measurements of mixtures having a $0.485 \mathrm{w} / \mathrm{c}$ ratio (Fig. 4) indicated a significant level of exothermic activity taking place within the first $15 \mathrm{~min}$, after which further activity was largely delayed until $2 \mathrm{~h}$. The rate of evolved heat was minimal after $8 \mathrm{~h}$ indicating a time frame over which ettringite formation by way of ye'elimite/anhydrite hydration was largely achieved.

\subsection{Later hydration: reactivity and strength gain}

The reactivity of fast acting phases in the experimental CSA cement $\left(\mathrm{C}_{4} \mathrm{~A}_{3} \overline{\mathrm{S}}, \mathrm{C} \overline{\mathrm{S}}\right.$ and $\left.\alpha^{\prime}-\mathrm{C}_{2} \mathrm{~S}\right)$ and the associated strength gain were strongly influenced by the presence of retarding admixtures. The combined

Table 2 Apparent set time in CSA cement pastes having a $0.485 \mathrm{w} / \mathrm{c}$ ratio [Minutes]

\begin{tabular}{lllll}
\hline Experimental CSA & Preliminary batch & Commercial CSA & \multicolumn{2}{l}{ Retarded-experimental CSA } \\
\cline { 2 - 5 } & & Citric acid & Citric acid and gypsum \\
\hline 2 & 114 & 194 & 11 & 63 \\
\hline
\end{tabular}

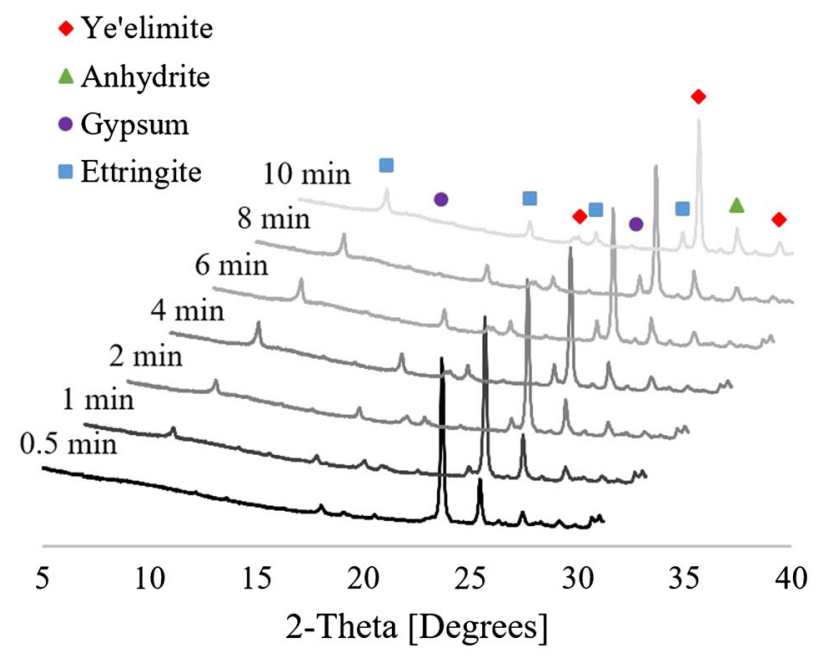

(a)

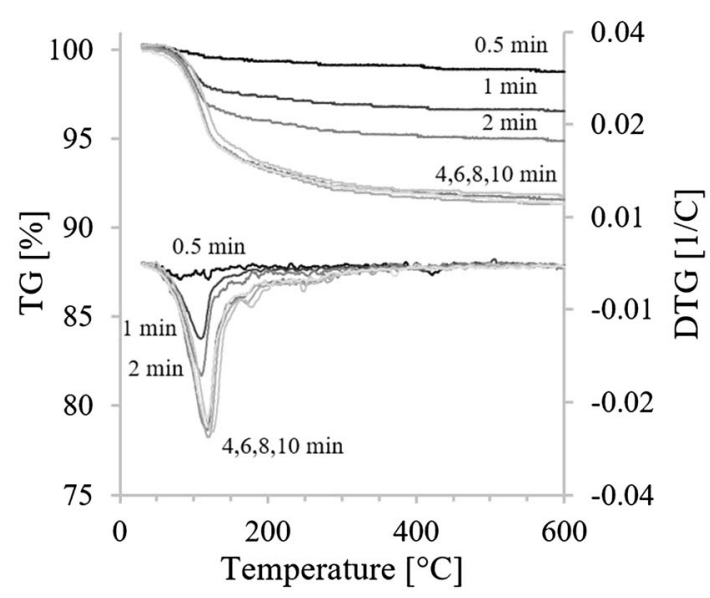

(b)

Fig. 3 Early age hydration of the experimental CSA clinker characterized by a XRD and b TGA 


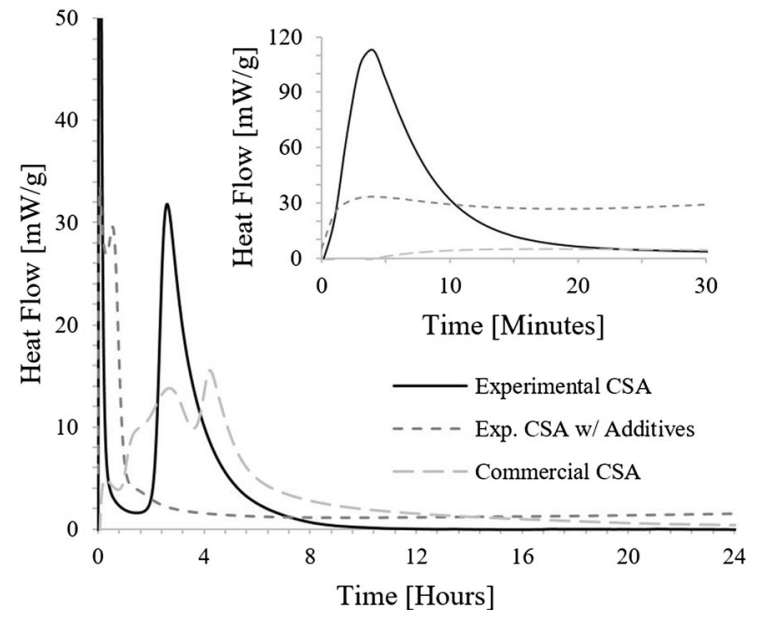

Fig. 4 Isothermal conduction calorimetry performance of experimental CSA cement mixtures and commercial CSA with blended $\mathrm{C} \overline{\mathrm{S}}$ at $25^{\circ} \mathrm{C}$ (with early age results inset)

inclusion of citric acid and gypsum (noted by the identifier "-R") delayed the near complete consumption of the ye'elimite from day one to beyond 3 days (Table 3). Strength performance reflected this retardation effect in the significantly delayed formation of consequential strength to the 7 day measurement. Without the use of retarding admixtures, the strength development of the experimental CSA cement reached $20 \mathrm{MPa}$ before 3 days, but further gains were subject to the limitation imposed by an overall increased porosity stemming from the higher w/c ratio employed.

\section{Discussion}

\subsection{Observations of the experimental clinkers}

Examination of the compositional distribution within the cement grains fails to identify continuous chunks of singular, consistent phases in the experimental CSA clinker (Fig. 1a) suggesting both a strong intermixing of mineralogical phases and small crystallite sizes within the polymineralic grains. In contrast, distinct regions being aluminium/sulfur rich and silica rich (representing $\mathrm{C}_{4} \mathrm{~A}_{3} \overline{\mathrm{S}}$ and $\mathrm{C}_{2} \mathrm{~S}$ respectively) exist in the commercial product. While perimeter/concentrated formations of sulfate rich phases are evident in the preliminary batch and the commercial product (into which the $\mathrm{C} \overline{\mathrm{S}}$ phase was blended), a relatively homogenous distribution can be observed in the experimental CSA despite a comparable total calcium sulfate content. It is inferred that this signifies the existence of nano-crystallites of calcium sulfate throughout the cement grains. Comparing BSE greyscale images it can be said that the relative density of

Table 3 Composite mortar strength development, cementitious phase hydration and hydrate quantification of the experimental CSA

\begin{tabular}{|c|c|c|c|c|c|c|c|c|}
\hline & 1 day & & 3 days & & 7 days & & 28 days & \\
\hline \multicolumn{9}{|c|}{ Compression strength development [MPa] } \\
\hline & w/c 0.65 & w/c $0.485-\mathrm{R}$ & w/c 0.65 & w/c $0.485-\mathrm{R}$ & w/c 0.65 & w/c $0.485-\mathrm{R}$ & w/c 0.65 & w/c $0.485-\mathrm{R}$ \\
\hline & 17.1 & 2.4 & 21.6 & 4.6 & 23.6 & 35.1 & 25.4 & 49.5 \\
\hline \multicolumn{9}{|c|}{ Hydration of major cementitious phases [\% consumed] } \\
\hline $\mathrm{C}_{4} \mathrm{~A}_{3} \overline{\mathrm{S}}$ & 98 & 59 & 100 & 83 & 100 & 98 & 100 & 100 \\
\hline$\alpha^{\prime}-C_{2} S$ & 61 & 42 & 85 & 43 & 92 & 45 & 92 & 73 \\
\hline$\beta-C_{2} S$ & 0 & 0 & 10 & 0 & 28 & 0 & 32 & 13 \\
\hline $\mathrm{C} \overline{\mathrm{S}}$ & 89 & 55 & 89 & 84 & 89 & 88 & 89 & 88 \\
\hline \multicolumn{9}{|c|}{ Hydrates ( $\mathrm{g} / 100 \mathrm{~g}$ anhydrous cement $\left.{ }^{a}\right)$} \\
\hline Ettringite & 26 & 25 & 25 & 37 & 25 & 44 & 24 & 42 \\
\hline Strätlingite & 4 & 0 & 18 & 0 & 23 & 0 & 25 & 11 \\
\hline AFm-12 & 0 & 0 & 2 & 0 & 2 & 0 & 3 & 2 \\
\hline AFm-10.5 & 4 & 0 & 6 & 0 & 4 & 0 & 5 & 0 \\
\hline Amorphous & 24 & 10 & 14 & 12 & 20 & 11 & 17 & 15 \\
\hline
\end{tabular}

\footnotetext{
a The relative error of the XRD-quantified mineral contents is estimated to be on the order of $5 \%$
} 
phases in the experimental CSA clinker (Fig. 1a) is lower than that of the commercial cement grain (Fig. 1c) suggesting that for similar compositions, a greater degree of porosity exists in the experimental clinker.

\subsection{Early hydration: dissolution and precipitation}

The conductivity and setting times of the commercial CSA cement and the preliminary batch can be grouped to reflect "normal" setting behaviour, displaying setting times on the order of $60 \mathrm{~min}$ or greater. The complimentary measurements of reactivity for the experimental CSA cement by way of a rapidly developed heat release and quantified ettringite formation both within the first $10 \mathrm{~min}$ of hydration, were suggestive of an irregular (below $25 \mathrm{~min}$ ) set performance with respect to the description of the Chinese test method standard, GB 20472 [32]. However, the early age hydration performance of the experimental CSA cement does not neatly fit the patterns associated with false and flash setting observed in PC. As shown by Allevi et al. [33], the rate of calcium sulfate solubilisation is a critical parameter influencing the reactivity of calcium sulfoaluminate cements. Conductivity increases are associated with increasing ion solubilisation and decreases with ion removal from solution. Correspondingly, the nonlinear conductivity time history of the experimental CSA cement suggests a near immediate dissolution of cement phases accompanied by rapid consumption of ions to form solid hydrates as early as 2 min (Fig. 2). Rapid thickening is encountered in a concurrent time frame during continuous mixing of cement paste which is observed to be consistent with the formation of ettringite and the evolution of a large spike of heat, suggesting the possibility of flash set. While the application of additional high shear mixing is capable of regaining normal consistency, during early crystal precipitation an appreciable development of gypsum was not observed. Despite the observation of a well dispersed, fine-grained $\mathrm{C} \overline{\mathrm{S}}$ within the cement it is suggested that the similarly fine-grained structure of $\mathrm{C}_{4} \mathrm{~A}_{3} \overline{\mathrm{S}}$ and $\mathrm{C}_{2} \mathrm{~S}$ do not allow for oversaturation of calcium and sulfate ions in the liquid phase alone, which might otherwise promote gypsum crystallization [34]. For the experimental cement investigated here, it is strongly suggested that hydration of anhydrite to gypsum is at most a transitory precursor to the ettringite formation observed such that gypsum formation is not the cause of stiffening. These findings are in stark disagreement with respect to the occurrence of PC "false setting". The behaviour of the experimental CSA exhibits conflicting aspects attributable to the conventional definitions of both false and flash setting, suggesting that the correct terminology to describe the encountered situation could be a "false-like set".

It is the immediate onset of clinker dissolution and rapid nature of hydrate precipitation by which the mechanism of false-like set is realized. The aforementioned similarity of rapid establishment of a high conductivity between the experimental CSA and reagent anhydrite immersed in distilled water is suggestive of a dissolution rate achievable by similar accessible surface area. Certainly the interpretation of nano-crystallites would be supportive of this, but so too would the morphological profile of the cement grain pictured in Fig. 1a. The lack of smoothness across the surface of the cement grain, taken as an indicator of a porous nature, would imply greater pathways for water entry into the interior of the cement grain in contrast to the often characterized nature of perimeter hydrate formation used when describing PC $[35,36]$.

That agreement exists between the early (sub-four minute) loss of conductivity being caused by precipitation, the measured stiffening and the quantifiable formation of ettringite is further indicative of the highly reactive nature of the ye'elimite incorporated into the experimental CSA cement. This ye'elimite component generates an ettringite volume formation for which the space filling capacity may be capable of forming cross grain networks, consequently similar to the pore refinement/subdivision described by Winslow and Diamond [37], while simultaneously generating significant exothermic activity (Fig. 4).

The apparent need for both the addition of citric acid and gypsum to combat the false-like set, generates a combined slowing response given the aforementioned understanding of the clinker and its dissolution. As the conductivity rise accompanying gypsum dissolution is of a similar or greater magnitude to that of the cement (Fig. 2), blending additions of gypsum to the cement would deter further solubilisation of the anhydrite component within the cement when initially wetted. Similarly, the added presence of citrate salts has been 
suggested to poison the growth of ettringite crystals [38]. Evidence of this can be observed microscopically in Fig. 5, where the morphology of ettringite crystals lose their characteristic needle shape (Fig. 5a) and become stunted in the presence of citric acid (Fig. 5b). Sorption of calcium carboxylate or other citrate compounds is reported to be responsible for coating and secluding otherwise accessible ye'elimite crystals $[39,40]$. It is implied through calorimetry (Fig. 4) that the early development of ettringite is also lowered on an equivalent mass basis, as less heat evolution is associated with an overall reduction in the extent of reaction. From this, it is concluded that the admixture set is strongly slowing the dissolution of cement phases responsible for the false-like setting, generating favourable mixing consistency.

\subsection{Later hydration: reactivity and strength gain}

Comparing the strength performance of the cement, herein expressed as a mortar, to the current commercial standard (PC $52.5 \mathrm{~N}$ or equivalent CSA) requires meeting objective targets of both high early (1 or 3 days) and late-age (28 days or greater) strength.

For those mixtures in which the false-like set was broken by the conventional process of additional mixing and a higher water content, early strength performance is consistent with the reactivity of the $\mathrm{C}_{4} \mathrm{~A}_{3} \overline{\mathrm{S}}$ and the $\alpha^{\prime}-\mathrm{C}_{2} \mathrm{~S}$ phases. As both are measured to undergo primary hydration within the first $24 \mathrm{~h}$, their

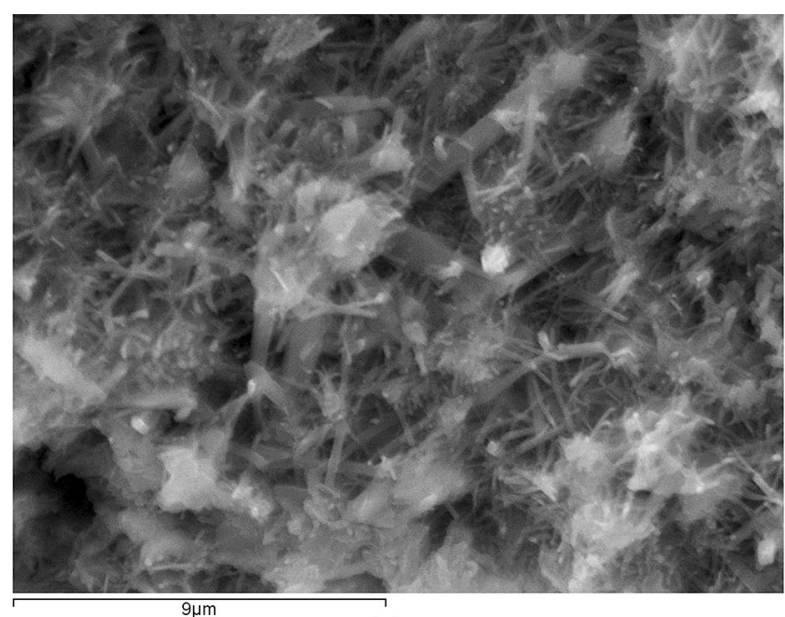

(a) capacity to promote 1 day strength is not surprising. Early $\mathrm{CaO}-\mathrm{Al}_{2} \mathrm{O}_{3}-\mathrm{SiO}_{2}-\mathrm{H}_{2} \mathrm{O}$ hydrate (i.e. strätlingite) detection is correlated with consumption of the $\alpha^{\prime}-\mathrm{C}_{2} \mathrm{~S}$ provided a supply of available aluminium ions in solution is present. Upon exhausting aluminium sources, continued $\mathrm{C}_{2} \mathrm{~S}$ hydration is assumed to contribute to the formation of amorphous $\mathrm{C}-(\mathrm{A})-\mathrm{S}-$ $\mathrm{H}$, typical of PC hydration. Within the first week of hydration (i.e. comparing one, 3 and 7 days in Table 3), increasing strätlingite content is correlated with increasing composite strength. However, having consumed a large extent of reactive phases within this early period of time as well as encompassing a high capillary porosity generated by the workability-based water demand, further strengthening is limited.

For those mixtures in which the false-like set was overcome by additives, generating a set time on the order of $60 \mathrm{~min}$, the early age strength is minimal but the 28 day strength profile compares favourably with conventional PC belonging to the $52.5 \mathrm{~N}$ CEM I cement class as defined by EN 197-1. Notably, sulfate addition through the presence of gypsum in the retarding admixtures increases the ettringite content at full ye'elimite consumption. This corresponds with a decrease in strätlingite content as the availability of unincorporated aluminium ions is lessened. Contrary to the aforementioned case, the absence of crystalline strätlingite formation (as comparing 3 and 7 days in Table 3) does not prevent a marked strength increase. $\beta-\mathrm{C}_{2} \mathrm{~S}$ participation, occurring at a slower rate, is

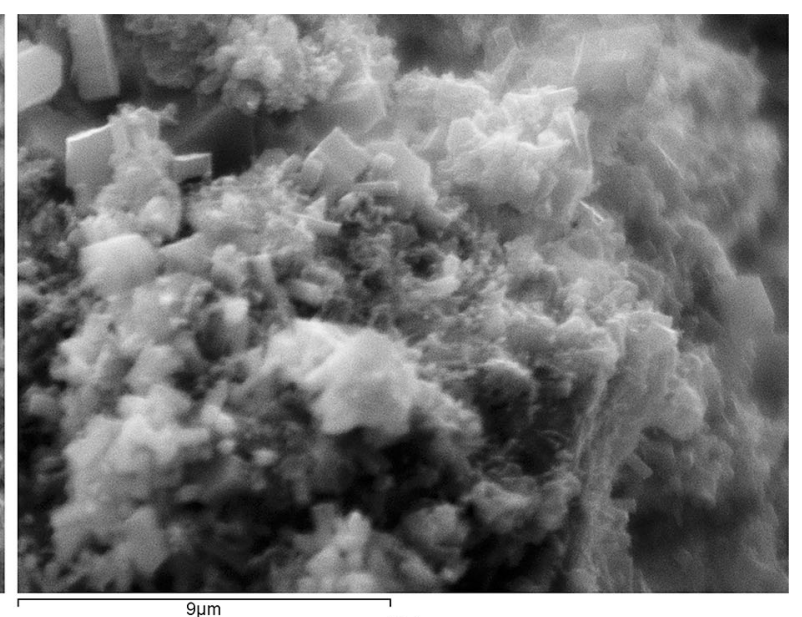

(b)

Fig. 5 Fracture micrographs of early ( $24 \mathrm{~h}$ ) ettringite formation morphology in a water and $\mathbf{b}$ water with low dose citric acid and gypsum, cured at $20^{\circ} \mathrm{C}$ 
anticipated to be the remaining component for which any future strength gains beyond 28 days will rely upon. This suggests that for the composition under investigation ( $28 \% \quad \beta-\mathrm{C}_{2} \mathrm{~S}$, Table 1$)$, a forward-looking trajectory of strength development might be similar to that experienced by PC.

\section{Conclusions}

The cementitious material produced by pilot kiln trials of a novel production process is characterized by an extremely high reactivity, producing behaviour similar in concept to false setting. The role of intrinsic calcium sulfate is highlighted in regard to its accessibility and dissolution in the early stages of cement wetting. By rapidly solubilizing calcium and sulfate ions into solution, the crystallization of ettringite is substantially accelerated producing a crystalline network displaying thickening termed "false-like set". Poisoning of this rapid ettringite formation was found to be an effective method of overcoming the initial burst of thickening and maintaining workability for a time sufficient to adequately mix and cast specimens. Likewise, the application of a high shear rate in the mixing process effectively demolished the initial crystalline network and re-established workability albeit at a greater water demand.

Two options have been presented to meet a workability-based performance standard in relation to the experimental CSA cement. However, incorporation of either of these methods is observed to introduce limitations in strength gain/performance. Further work is necessary to establish the impact of the properties and behavior described herein on other relevant engineering parameters, i.e. dimensional stability, durability, etc.

Acknowledgements The authors are grateful for the financial support of the Gulf Organization for Research and Development (GORD) through grant EG016-RG11757. Mr Mathieu Antoni of LafargeHolcim is thanked for his assistance in processing the grinding of the experimental clinker. Mr Theodore Hanein is thanked for insight gained in discussions regarding thermodynamic modelling of the $\mathrm{CaO}-\mathrm{Al}_{2} \mathrm{O}_{3}-\mathrm{SO}_{3}-\mathrm{SiO}_{2}$ system within the kiln environment.

\section{Compliance with ethical standards}

Conflict of interest The authors declare they have no conflict of interest.
Open Access This article is distributed under the terms of the Creative Commons Attribution 4.0 International License (http:// creativecommons.org/licenses/by/4.0/), which permits unrestricted use, distribution, and reproduction in any medium, provided you give appropriate credit to the original author(s) and the source, provide a link to the Creative Commons license, and indicate if changes were made.

\section{References}

1. Hendricks CA, Worrell E, de Jager D, Blok K, Riemer P (1998) Emission reduction of greenhouse gases from the cement industry. In: Proceedings of the 4th International Conference on Greenhouse Gas Control Technologies. Interlaken, Austria. August 30-September 2

2. Olivier JGJ, Janssens-Maenhout G, Muntean M, Peters JAHW (2015) Trends in global $\mathrm{CO}_{2}$ emissions: 2015 Report. The Hague: PBL Netherlands Environmental Assessment Agency. Ispra: European Commission Joint Research Centre

3. Worrell E, Price L, Martin N, Hendricks C, Meida LO (2001) Carbon dioxide emissions from the global cement industry. Annu Rev Energy Environ 26:303-329

4. Benhelel E, Zahedi G, Shamsaei E, Bahadori A (2013) Global strategies and potentials to curb $\mathrm{CO}_{2}$ emissions in cement industry. J Clean Prod 51(15):142-161

5. Friedlingstein P, Andrew RM, Rogelj J, Peters GP, Canadell JG, Knutti R, Luderer G, Raupach MR, Schaeffer M, van Vuuren DP, Le Quere C (2014) Persistent growth of $\mathrm{CO}_{2}$ emissions and implications for reaching climate targets. Nat Geosci 7:709-715

6. Bullerjahn F, Schmitt D, Ben Haha M (2014) Effect of raw mix design and of clinkering process on the formation and mineralogical composition of (ternesite) belite calcium sulphoaluminate ferrite clinker. Cem Concr Res 59:87-95

7. Gartner E (2004) Industrially interesting approaches to "low- $\mathrm{CO}_{2}$ " cements. Cem Concr Res 34(9):1489-1498

8. Morin V, Walenta G, Gartner E, Termkhajornkit P, Baco I, Casabonne JM (2011) Hydration of a belite-calcium sulfoaluminate-ferrite cement: Aether ${ }^{\mathrm{TM}}$. In: Proceedings of the 13th International Congress on the Chemistry of Cement. Madrid Spain, July 3-8

9. Zhang L, Su M, Wang Y (1999) Development and use of sulfo- and ferroaluminate cements in China. Adv Cem Res 11(1):15-21

10. Li X, Zhang Y, Shen X, Wang Q, Pan Z (2014) Kinetics of calcium sulfoaluminate formation from tricalcium aluminate, calcium sulfate and calcium oxide. Cem Concr Res 55:79-87

11. Popescu CD, Muntean M, Sharp JH (2003) Industrial trial production of low energy belite cement. Cem Concr Compos 25(7):689-693

12. Song JT, Young JF (2002) Direct synthesis and hydration of calcium aluminosulfate $\left(\mathrm{Ca}_{4} \mathrm{Al}_{6} \mathrm{O}_{16} \mathrm{~S}\right)$. J Am Ceram Soc 85(3):535-539

13. Touzo B, Scrivener KL, Glasser FP (2013) Phase compositions and equilibria in the $\mathrm{CaO}-\mathrm{Al} 2 \mathrm{O} 3-\mathrm{Fe} 2 \mathrm{O} 3-\mathrm{SO} 3$ system, for assemblages containing ye'elimite and ferrite $\mathrm{Ca} 2(\mathrm{Al}, \mathrm{Fe}) \mathrm{O} 5$. Cem Concr Res 54:77-86 
14. Hanein T, Imbabi MS, Glasser FP, Bannerman MN (2016b) Lowering the carbon footprint and energy consumption of cement production: A novel calcium sulfoaluminate cement production process. In: Proceedings of the 1st International Conference on Grand Challenges in Construction Materials. Los Angeles, USA. March 17-18

15. Galan I, Elhoweris A, Hanein T, Bannerman MN, Glasser FP (2016b) Advances in clinkering technology of calcium sulfoaluminate cements. Adv Cem Res (under review)

16. Galan I, Glasser FP, Elhoweris A, Tully S, Murdoch A (2014) Novel process for calcium sulfoaluminate production. In: Proceedings of the 34th Cement and Concrete Science Conference. Sheffield, UK. September 14-17

17. Hanein T, Galan I, Elhoweris A, Khare S, Skalamprinos S, Jen G, Whittaker M, Imbabi MS, Glasser FP, Bannerman MN (2016) Production of belite calcium sulfoaluminate cement using sulfur as a fuel and as a source of clinker sulfur trioxide: pilot kiln trial. Adv Cem Res 28(10):643-653

18. Bensted J, Barnes P (2002) Structure and performance of cements, 2nd edn. Spon Press, London

19. Mehta PK, Monteiro PJM (2014) Concrete: Microstructure, Properties and Materials, 4th edn. McGraw-Hill Education, New York

20. Taylor HFW (1997) Cement Chemistry, 2nd edn. Thomas Telford, London

21. Collepardi M, Baldini G, Pauri M, Corradi M (1978) Tricalcium aluminate hydration in the presence of lime, gypsum or sodium sulfate. Cem Concr Res 8(5):571-580

22. Smith MA, Matthews JD (1974) Conduction calorimetric studies of the effect of sulphate on the hydration reactions of Portland cement. Cem Concr Res 4(1):45-55

23. Tzouvalas G, Dermatas N, Tsimas S (2004) Alternative calcium sulfate-bearing materials as cement retarders: part 1. Anhydrite. Cem Concr Res 34(11):2113-2118

24. Larson AC, Von Dreele RB (1987) General Structure Analysis System (GSAS). Los Alamos National Laboratory Report No. LA-UR-86-748. The Regents of the University of California, Los Alamos

25. Thompson P, Cox DE, Hasting JB (1987) Rietveld refinement of Debye-Scherrer synchrotron X-ray data from $\mathrm{Al}_{2} \mathrm{O}_{3}$. J Appl Crystallogr 20:79-83

26. Finger LW, Cox DE, Jephcoat AP (1994) A correction for powder diffraction peak asymmetry due to diaxial divergence. J Appl Crystallogr 27:892-900

27. Galan I, Beltagui H, Garcia-Mate M, Glasser FP, Imbabi MS (2016) Impact of drying on pore structures of ettringite rich cement. Cem Concr Res 84:85-94

28. Alvarez-Pinazo G, Cuesta A, Garcia-Mate M, Santacruz I, Losilla ER, de la Torre Leon-Reina L, Aranda MAG (2012) Rietveld quantitative phase analysis of Ye'elimite-containing cements. Cem Concr Res 42(7):960-971

29. Aranda MAG, de la Torre AG, Leon-Reina L (2012) Rietveld quantitative phase analysis of OPC clinkers, cements and hydration products. Rev Mineral Geochem 74:169-209

30. Jansen D, Goetz-Neunhoeffer F, Stabler C, Neubauer J (2011) A remastered external standard method applied to the quantification of early OPC hydration. Cem Concr Res 41:602-608

31. O'Connor B, Raven MD (1988) Application of the Rietveld refinement procedure in assaying powdered mixtures. Powder Diffr J 3:2-6
32. China Building Materials Academy (2006) GB 20472-2006 Sulphoaluminate cement. National Standardization Technical Committee, Beijing

33. Allevi S, Marchi M, Scotti F, Bertini S, Cosentino C (2016) Hydration of calcium sulphoaluminate clinker with additions of different calcium sulphate sources. Mater Struct 49(1):453-466

34. Sahu S, Tomkova V, Majling J, Havlica J (1993) Influence of particle sizes of individual minerals on the hydration processes in the system $\mathrm{C}_{2} \mathrm{~S}-\mathrm{C}_{4} \mathrm{~A}_{3} \overline{\mathrm{S}}-\mathrm{C} \overline{\mathrm{S}}$. Cem Concr Res 23(3):693-699

35. Bentz DP (1997) Three-dimensional computer simulation of Portland cement hydration and microstructure development. J Am Ceram Soc 80(1):3-21

36. Bullard JW, Jennings HM, Livingston RA, Nonat A, Scherer GW, Schweitzer JS, Scrivener KL, Thomas JJ (2011) Mechanisms of cement hydration. Cem Concr Res 41(12):1208-1223

37. Winslow DN, Diamond S (1970) A mercury porosimetry study of the evolution of porosity in Portland cement. ASTM J Mater 5(3):564-585

38. Cody AM, Lee H, Cody RD, Spry PG (2004) The effects of chemical environment on the nucleation, growth and stability of ettrringite $\left[\mathrm{Ca}_{3} \mathrm{Al}(\mathrm{OH})_{6}\right]_{2}\left(\mathrm{SO}_{4}\right)_{3} \cdot 26 \mathrm{H}_{2} \mathrm{O}$. Cem Concr Res 34(5):869-881

39. Moschner G, Lothenbach B, Figi R, Kretzchmar R (2009) Influence of citric acid on the hydration of Portland cement. Cem Concr Res 39(4):275-282

40. Velazco G, Almanza JM, Cortes DA, Escobedo JC, Escalante-Garcia JI (2014) Effect of citric acid and the hemihydrate amount on the properties of a calcium sulphoaluminate cement. Materiales de Construccion. 64(316):e036. doi:10.3989/mc.2014.03513

41. Cuesta A, de la Torre AG, Losilla ER, Peterson VK, Rejmak P, Ayuela A, Frontera C, Aranda MAG (2013) Structure, atomistic simulations, and phase transition of stoichiometric yeelimite. Chem Mater 25(9):1680-1687

42. Cuesta A, de la Torre AG, Losilla ER, Santacruz I, Aranda MAG (2014) Pseudocubic crystal structure and phase transition in doped ye' elimite. Cryst Growth Des 14:5158-5163

43. Cuesta A, Losilla ER, Aranda MAG, Sanz J, de la Torre AG (2012) Reactive belite stabilization mechanisms by boronbearing dopants. Cem Concr Res 42(4):598-606

44. Mumme WG, Hill RJ, Bushnell-Wye G, Segnit ER (1995) Rietveld crystal structure refinements, crystal chemistry and calculated powder diffraction data for the polymorphs of dicalcium silicate and related phases. Neues Jahrbuch fur Mineral Abhandlungen 169(1):35-68

45. Colville AA, Geller S (1971) The crystal structure of brownmillerite, $\mathrm{Ca}_{2} \mathrm{FeAlO}_{5}$. Acta Crystallogr B27:2311-2315

46. Kirfel A, Will G (1980) Charge density in anhydrite, $\mathrm{CaSO}_{4}$, from X-ray and neutron diffraction measurements. Acta Crystallogr B36:2881-2890

47. Louisnathan SJ (1971) Refinement of the crystal structure of a natural gehlenite, $\mathrm{Ca} 2 \mathrm{Al}(\mathrm{Al}, \mathrm{Si}) 2 \mathrm{O} 7$. Can Mineral 10:822-837

48. Sasaki S, Prewitt CT, Bass JD (1987) Orthorhombic perovskite $\mathrm{CaTiO}_{3}$ and $\mathrm{CdTiO}_{3}$ : structure and space group. Acta Crystallogr C43:1668-1674

49. Smith DK, Leide HR (1968) Low-temperature thermal expansion of $\mathrm{LiH}, \mathrm{MgO}$ and $\mathrm{CaO}$. J Appl Crystallogr 1:246-249 